\title{
Immunohistochemistry comparing endoscopic vein harvesting vs. open vein harvesting on saphenous vein endothelium
}

\author{
Mohammad Hassan Nezafati ${ }^{1}$, Pouya Nezafati2 ${ }^{2 *}$, Sakineh Amoueian ${ }^{3}$, Armin Attaranzadeh ${ }^{4}$
}

and Hamid Reza Rahimi ${ }^{5}$

\begin{abstract}
Objective: The present study attempts to compare the immunohistochemistry (IHC) of von Willebrand factor (vWf), endothelial cadherin, Caveolin and endothelial Nitric Oxide Synthase (eNOS) in VasoView Endoscopic Vein Harvesting $(\mathrm{EVH})$ versus traditional Open Vein Harvesting $(\mathrm{OVH})$ techniques for Coronary Artery Bypass Graft (CABG) Surgery performed in Javad al Aemeh Hospital of Mashhad, Iran in 2013,

Methods and materials: Forty-seven patients were scheduled for CABG (30 EVH and $17 \mathrm{OVH}$ ) among whom patients with relatively same gender and similar age were selected. Three separate two $\mathrm{cm}$ vein samples were harvested from each patient's saphenous vein. Each portion was collected from distal, middle and proximal zones of the saphenous vein. The tissues were deparaffinized, and antigen retrieval was done using EZ-retriever followed by an immunohistochemistry evaluation with vWf, e-cadherin, Caveolin and eNOS. In addition, demographic questioner as of Lipid profile, FBS, BMI, and cardiovascular risk factors were collected. Data analyses, including parametric and nonparametric tests were undertaken using the SPSS 16 software. A P value $<0.05$ was regarded as statistically significant.
\end{abstract}

Results: The mean age of the EVH and $\mathrm{OVH}$ groups were $63.76 \pm 9.51$ and $63.63 \pm 8.31$ years respectively with no significant difference between them $(p=0.989)$. In addition, there was no great difference between the EVH and OVH groups in lipid profile, DM, HTN, smoking history, CVA, and valvular dysfunction ( $P>0.05$ ). Qualitative report of $\mathrm{vWf}$, e-cadherin, Caveolin and eNOS reveals no significant difference between the $\mathrm{EVH}$ and $\mathrm{OVH}(\mathrm{P}>0.05)$.

Conclusion: This study indicates that VasoView EVH technique causes no endothelial damage in comparison with $\mathrm{OVH}$. This study could be a molecular confirmation for the innocuous of EVH technique.

Keywords: EVH, OVH, vWf, E-cadherin, Caveolin, eNOSs

\section{Background}

Many people around the world suffer from coronary artery disease $(\mathrm{CAD})$ that causes an enormous morbidity and mortality. In order to rescue individuals with this disease there is the major and best operation/cardiac surgery known as coronary artery bypass grafting (CABG) [1]. This specified surgery is performed on individuals with each of followed diseases: 1 ) left main coronary artery disease, 2) 3-vessel disease, 3) 3-vessel disease in diabetics, 4)

\footnotetext{
*Correspondence: pouya_dg@yahoo.com

${ }^{2}$ Student Research Committee, Mashhad University of Medical Sciences, No 124. Niloufar 8th, Sadjad Blvd, Mashhad 91878, Iran

Full list of author information is available at the end of the article
}

severely depressed heart function, and 5) heart conditions in addition to CAD e.g. replacement of valves or reconstruction of the heart muscle [1].

More than 300,000 CABG operations are performed in the North America annually [2]. Furthermore, it has been reported that over 10,000 patients require CABG every year in Iran [3]. However, complication rates, morbidity and mortality after CABG surgery are still expected to enhance despite advances in this field of the surgery to overcome CAD and rescue the patients [4], so surgeons should reduce the other risk factors of mortality and morbidity of CABG such as wound complications of saphenous vein. 
Endoscopic greater saphenous vein harvesting (EVH) decreases the wound complications related with open techniques [5]. In order to decrease the considerable morbidity and wound complications associated with the extensive incisions made in traditional approach to vein harvest, minimally invasive techniques such as EVH is recommended [6]. Also using minimally invasive methods could reduce intra-operative complications [7,8]. EVH uses $\mathrm{CO}_{2}$ and an endoscope to harvest the saphenous vein by a single tiny incision [9].

In traditional methods of greater saphenous vein harvesting, large incisions must be taken; however, local pain in leg, dysmobility, wound infection, wound bleeding, prolonged hospital stay, and insufficient cosmetic results could happen [10,11].

A meta-analysis showed that EVH is safe and reduced rates of wound complications; leg wound infection, wound hematoma, and post operational pain, compared to traditional open techniques [6]. This research team in their previous study found EVH has fewer postoperative wound complications and less postoperative pain in comparison with $\mathrm{OVH}[8]$.

Allen KB et al. reported that "five-year follow-up of a prospective randomized clinical trial (RCT) display that use of EVH does not influence event-free survival" [5]. Some other scientists believe that EVH is independently associated with vein-graft failure [12]. Disruption of the endothelium by any instruments may cause the vein-graft failure so some heart surgeons still have doubts about $\mathrm{EVH}$ and they believe that it might cause damage to saphenous vein endothelium tissue [13]. Endothelial Nitric Oxide (eNOS), endothelial Caveolin (e-Caveolin), von Willebrand factor (vWf), and cadherin can evaluate endothelial function and damages [14]. Endothelial damage can be shown by displaced or decreased expression of eNOS and Caveolin [14]. vWF can demonstrate endothelial cell damage [15]. Serine/threonine protein kinase Akt can activate eNOS and endothelial dysfunction is due to the inadequate NO synthesis [16].

Although, vascular endothelial (VE)-cadherin is more specific to vascular endothelium but expression of this adhesion molecule might be an index for permeability and leukocyte extravasations. Therefore, we decided to evaluate e-cadherin [17].

The present study attempts to compare the immunohistochemistry of vWf, e-cadherin, Caveolin and eNOS in VasoView endoscopic saphenous vein versus traditional open vein harvesting techniques for CABG Surgery performed in Javad al Aemeh Hospital of Mashhad, Iran in 2013.

\section{Methods}

From June 2013 to October 2013, 47 patients underwent CABG in Mashhad, Northeast of Iran. EVH performed on 30 patients and 17 had $\mathrm{OVH}$. According to a preivouse research [13] and Daniel formula (Daniel 1999, Z value was 1.96, Expected proportion was 0.01, and Precision (d) was 0.0025 ) we used to determine the sample size of this study, so we needed $15.84(\approx 16)$ cases in each group. Then we selected 17 controls in $\mathrm{OVH}$ and increased $\mathrm{EVH}$ group up to 30 cases.

This is a prospective cohort study, and demographic information (age, gender, educational level, marital status, income, and occupation), family history of CAD, smoking habits, FBS level and serum lipid profiles were almost similar in all patients.

All 47 patients had a same chance to be either in EVH or $\mathrm{OVH}$ group, they were numbered blindly, and then 17 numbers were selected from random number table for $\mathrm{OVH}$ and other 30 numbers were selected for EVH group.

As a primary choice for anastomosis, mammary arteries were used for the first vessel grafting in all 47 patients, and saphenous veins were used for the remaining number of anastomoses needed.

Three separate two $\mathrm{cm}$ vein samples were harvested from each of patient's saphenous vein (distal, medial, proximal vein) for each EVH and OVH techniques, immediately after the harvesting.

\section{Endoscopic operative technique}

Endoscopic dissection and excision of the saphenous vein has the advantage of requiring smaller skin incision, which heals better.

Our EVH method is based on the $\mathrm{CO} 2$ technique using a sealed and constant method of $\mathrm{CO} 2$ insufflations (VasoView HemoPro 2; Maquet $^{\odot}$ ).

A small incision is made $1.5-2.5 \mathrm{~cm}$ below/above the knee to build the entrance of the probe, which then continues its path toward the groin region. For dividing the branches, we used a bipolar cauterizer and by the use of a Scissor, a punctured incision was made to clamp, ligate and divide the vein. Ligation for small-size side branches was performed by clips whereas large-size branches and sites of basal disruption ligated with 7.0 monofilament prolene suture (this surgical team method), in addition to the application of clips for a greater blockage of the branches after harvesting the vein (Figure 1).

\section{Open operative technique}

At first, the leg was abducted and rotated laterally by placing a roll under knee. After a long incision was made over the saphenous vein, side branches were ligated/clipped.

The vein was then removed and prepared after the closure of the incision site in layers with absorbable suture and the leg wound was covered with cotton gauze dressing, in addition to applying an elastic ace to the entire leg (Figure 1). 


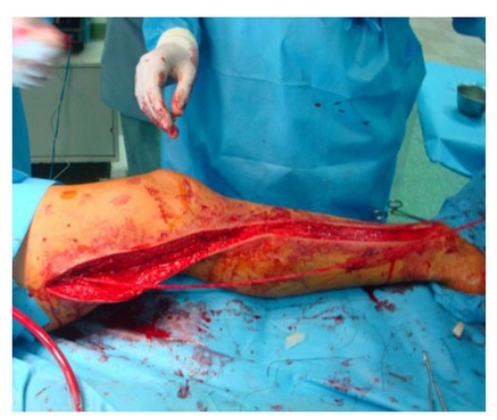

Figure $1 \mathrm{EVH}$ and $\mathrm{OVH}$ procedure (EVH at right and $\mathrm{OVH}$ at left).

\section{Immunohistochemical staining}

Three micrometer thick tissue sections were placed on slides covered by Poly-L-Lysin, deparaffinized by xylol, and was dehydrated by graded alcohols for 10 minutes. Endogenous peroxidase activity was inhibited in $\mathrm{H}_{2} \mathrm{O}_{2}$ methanol solution. The de-paraffinized slides were rinsed with PBS and encountered with non-immune serum 10\% for 10 minutes. Then cuts were incubated in a humidified chamber with an appropriate dilution of antibody (50 to 100 microliter) for 30-60 min at room temperature. Slides were washed in PBS for 5 min (Three replacements) and were incubated in a solution containing 3, 3 with 3 amino -9 - ethyl. Counterstain was performed with Gill's triple-strength hematoxylin. All these experimental procedures were performed under the instruction and protocols of Leica Biosystem (Novocastra) Corporation which is available in every immunohistochemistry kit. Immunohistochemistry staining was done for vWf, e-cadherin, Caveolin and eNOS. Negative staining reported by "-", weakly positive staining reported by ", positive samples were reported by " +", and finally strongly positive samples were reported by "++". Single expert pathologist in IHC staining examined all samples (Figure 2).

\section{Statistical analysis}

Statistical analysis used was the Statistical Package for Social Sciences version 16(SPSS Inc., Champaign, IL, USA). The Kolmogorov-Smirnov test was used to assess normality. Descriptive statistics (frequency, mean, and standard

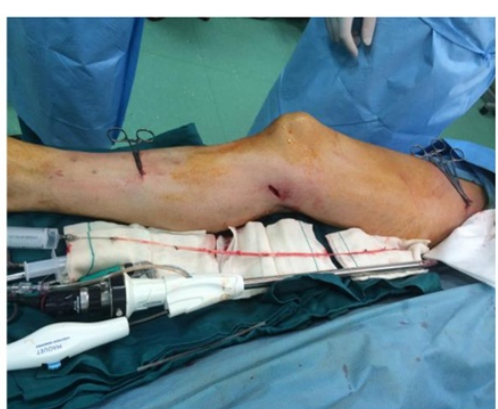

deviation) were determined for all variables. Values are reported as mean \pm SD for normally distributed variables (or Median and Interquartile range (IQR) for not normal distribute variables). Baseline demographics and clinical characteristics were compared between groups using t-student test, chi-square test, Friedman test, and/or Fisher exact test as appropriate. A p value $<0.05$ was considered as significant.

\section{Results}

Mean age has no significant difference between EVH and $\mathrm{OVH} 63.76 \pm 9.51$ and $63.63 \pm 8.31$ respectively $(\mathrm{P}=$ 0.961 ). In addition, there is no noticeable difference between groups in gender, smoking, hypertension, hyperlipidemia, CVA history, BMI, and family history of CAD (P > 0.05) (Table 1).

Most of the patients were referred to our center due to three-vessel coronary disease (Table 1).

BUN, Cr, FBS, total cholesterol, LDL-C, HDL-C, and triglyceride had no significant difference between EVH and OVH group $(\mathrm{P}>0.05)$ (Table 1$)$.

Multivariate regression analysis demonstrated no influence of basic characteristics variable on IHC outcome.

According to Table 2, eNOS, E-cadherin, Caveolin, and vWF immunohistochemistry staining in distal, medial and proximal zones of vein samples in both groups had no significant statistical difference $(\mathrm{P}>0.05)$ (Table 2) (Figure 2).

Hospital follow-ups were performed including echocardiography, CKB-MB and Troponin cardiac enzymes.

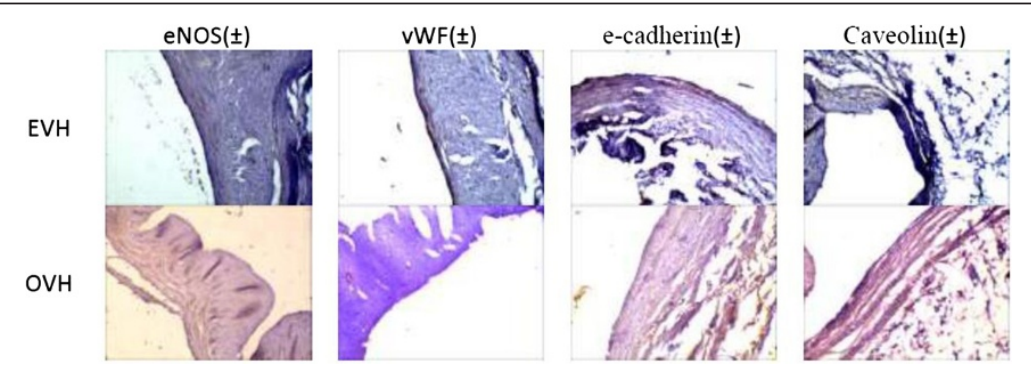

Figure 2 eNOS, vWF, e-cadherin, and ccaveolin in EVH and OVH immunohistochemistry slides. Qualitative assessing of slides were done by a same expert pathologist, as micrographs showed same staining intensity in intercellular and intracellular space. 
Table 1 Characteristics data from all subjects in each group

\begin{tabular}{|c|c|c|c|}
\hline Variable & $\mathrm{EVH}(n=30)$ & OVH $(n=17)$ & $P$ value \\
\hline Age (year) & $63.76 \pm 9.51$ & $63.63 \pm 8.31$ & 0.961 \\
\hline \multicolumn{4}{|l|}{ Sex } \\
\hline Male & $23(76.7)$ & $11(64.7)$ & \multirow[t]{2}{*}{0.378} \\
\hline Female & $7(23.3)$ & $6(35.3)$ & \\
\hline \multicolumn{4}{|l|}{ Smoking } \\
\hline Yes & $9(32.1)$ & $7(41.2)$ & \multirow[t]{2}{*}{0.539} \\
\hline No & 19(67.9) & $10(58.8)$ & \\
\hline \multicolumn{4}{|l|}{ Diabetes mellitus } \\
\hline Yes & $14(51.9)$ & $2(11.8)$ & \multirow[t]{2}{*}{0.007} \\
\hline No & $13(48.1)$ & $15(88.2)$ & \\
\hline \multicolumn{4}{|l|}{ Hypertension history } \\
\hline Positive & $16(59.3)$ & $11(64.7)$ & \multirow[t]{2}{*}{0.718} \\
\hline Negative & $11(40.7)$ & $6(35.3)$ & \\
\hline \multicolumn{4}{|l|}{ Hyperlipidemia history } \\
\hline Positive & 15(53.6) & $8(47.1)$ & \multirow[t]{2}{*}{0.672} \\
\hline Negative & $13(46.4)$ & $9(52.9)$ & \\
\hline \multicolumn{4}{|l|}{ CVA (stroke) history } \\
\hline Positive & $0(0.0)$ & $0(0.0)$ & \multirow[t]{2}{*}{-} \\
\hline Negative & $28(100)$ & $17(100)$ & \\
\hline \multicolumn{4}{|l|}{ Family history of CAD } \\
\hline Positive & $8(26.6)$ & $4(23.5)$ & \multirow[t]{2}{*}{0.931} \\
\hline Negative & $22(74.4)$ & $13(76.5)$ & \\
\hline \multicolumn{4}{|l|}{ Valvular disease comorbidity } \\
\hline Positive & $2(7.1)$ & $2(11.8)$ & \multirow[t]{2}{*}{0.597} \\
\hline Negative & 26(92.9) & $15(88.2)$ & \\
\hline \multicolumn{4}{|l|}{ CABG reason } \\
\hline $2 \mathrm{VD}$ & $1(3.6)$ & $2(11.8)$ & \multirow[t]{2}{*}{0.285} \\
\hline $3 \mathrm{VD}$ & $27(96.4)$ & $15(88.2)$ & \\
\hline BMl & $27.50 \pm 4.93$ & $26.00 \pm 3.86$ & 0.291 \\
\hline BUN & $35.78 \pm 20.41$ & $29.85 \pm 14.67$ & 0.346 \\
\hline Creatinine & $0.99 \pm 0.27$ & $1.09 \pm 0.25$ & 0.240 \\
\hline FBS (mg/dl) & $136.0 \pm 55.83$ & $111.81 \pm 36.1$ & 0.128 \\
\hline TC (mg/dl) & $158.11 \pm 45.68$ & $207 \pm 122.73$ & 0.063 \\
\hline LDL-C (mg/dl) & $69.77 \pm 36.50$ & $94.07 \pm 40.21$ & 0.058 \\
\hline $\mathrm{HDL}-\mathrm{C}(\mathrm{mg} / \mathrm{dl})$ & $51.25 \pm 13.56$ & $50.85 \pm 6.13$ & 0.917 \\
\hline TG (mg/dl) (median(IQR)) & 165(72) & $175(85)$ & 0.294 \\
\hline
\end{tabular}

Date are shown as Number (percent), or mean $\pm S D$, or (median (IQR)). CVA: cerebrovascular accident, CABG: Coronary artery bypasses surgery, BMI: Body Mass Index, BUN: blood urea nitrogen, FBS: Fasting blood sugar, TC: total cholesterol, LDL-C: Low density lipoprotein cholesterol, HDL-C: High-density lipoprotein, TG: triacylglyceride, CAD: Coronary artery disease, 2VD: two-vessel coronary artery disease, 3VD: three-vessel coronary artery disease.

A rise of double for $\mathrm{CKB}-\mathrm{MB}$ and Troponin detected in one patient who underwent $\mathrm{OVH}$. This rise was managed to the normal range in the period of hospital
Table 2 Immunohistochemistry results from all subjects in each group

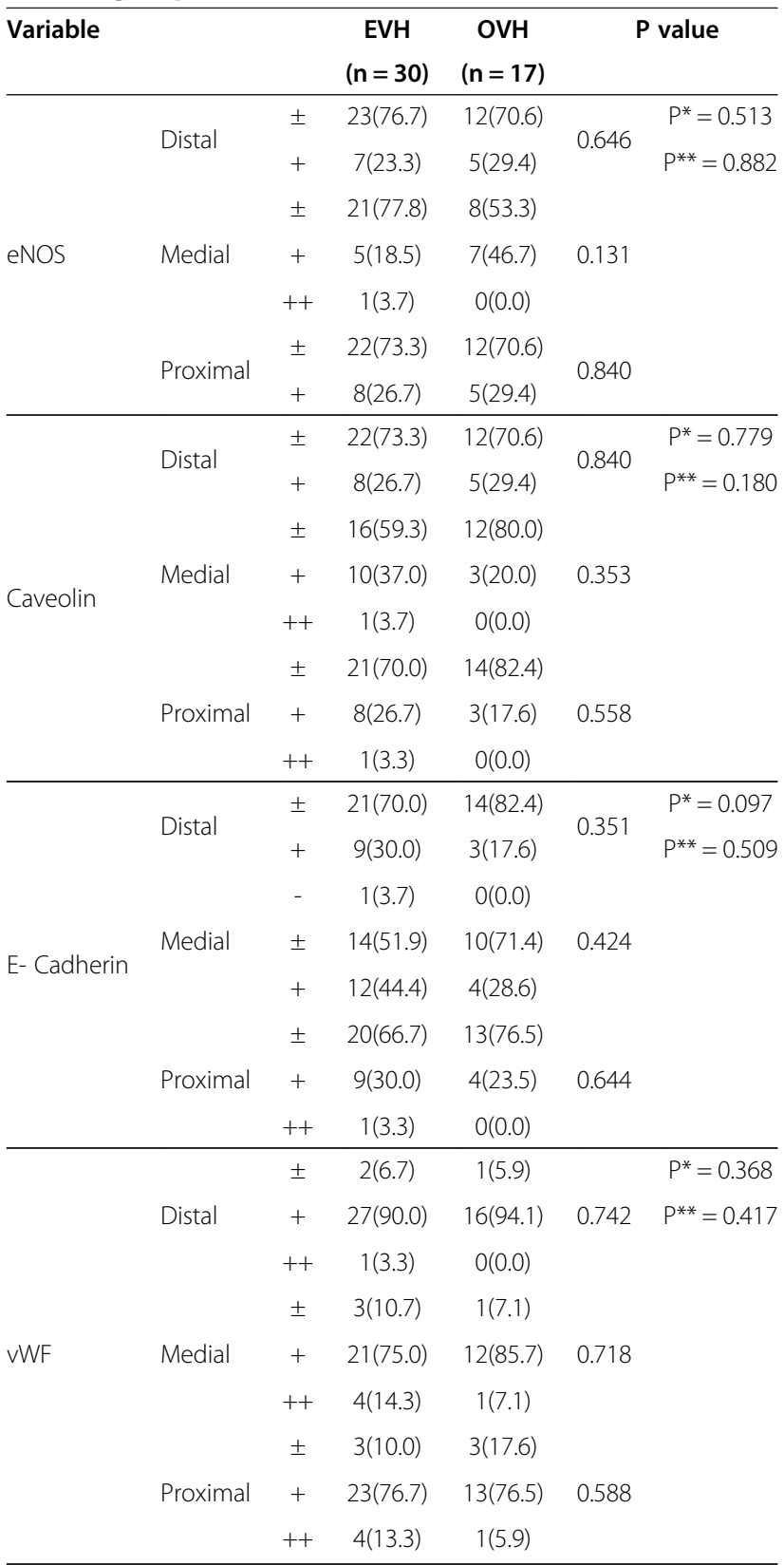

Date are shown as Number (percent).

NOS: nitric oxide synthase, vWF: Von Willebrand factor.

P*: P value of Friedman test for comparing distal, medial, and proximal sample within group of $\mathrm{OVH}$.

$\mathrm{P}^{* *}$ : P value of Friedman test for comparing distal, medial, and proximal sample within group of $\mathrm{EVH}$.

stay and no wall motion abnormality or EF changing appeared in echocardiography.

Finally, we have compared three samples taken from each person in both groups, which were analyzed by Friedman test, and we found no significant difference between IHC results in same patient in different parts of vein $(P>0.05)$ (Table 2$)$. In simple $H \& E$ histological 
slides, there was no structural and morphological difference between groups.

\section{Discussion and conclusion}

Chronic wounds or post operation complicated wounds are associated with increased morbidity and mortality and pose a serious economic burden on the health-care system. It has been estimated that nearly $\$ 25$ billion is spent annually in the United States to treat ulcers [18].

These chronic and non-healing wounds are the ones in which the healing progress is less than $(20-40 \%$ reduction in the area) after 2-4 weeks of appropriate approach and treatment [19].

Traditional greater saphenous vein harvesting may increase the post operation wound complications [20]. These wounds and their complications can influence the patient's physical activity and may make limitations for patients, so it is very harmful in post CABG rehabilitation therapy [21]. Surgeons' fatigue before they reach to the main part of the operation procedure is crucial; however, a great amount of time is gained for skin closure in $\mathrm{OVH}$ technique [22] whereas, $\mathrm{EVH}$ is performed at a satisfactory shorter time [23]. Considering all of these points, minimal invasive vein harvesting is noticeable.

Some surgeons and scientists believe that EVH may destroy greater saphenous vein tissue and it could be harmful for bypass grafting [12]. In this study, we aimed to compare the IHC tissue staining result between EVH and OVH greater saphenous vein.

According to our results, there were no significant differences between same site samples in $\mathrm{EVH}$ and $\mathrm{OVH}$ between patients and no noticeable difference in distal, medial and proximal sites within a patient sample was detected in eNOS, E-cadherin, Caveolin, and vWF.

Bader E. Hussain et al. in 2011 reported that EVH preserve the structural and functional viability of greater saphenous vein [13]. They found that western blots, immunofluorescent, multiphoton imaging had no difference for caveolin 1, eNOS, Cadherin, and vWf between EVH and OVH [13].

There were no changes in caveolin and eNOS in the vein endothelial in EVH technique in this study. These results are very important for evidence-based decision and in molecular view, there are no structural and cellular viability harm effect found in EVH compared with $\mathrm{OVH}$.

Iamar M. Al Saggaf et al. found statistically insignificant difference between EVH and OVH by scanning electron microscopy (SEM) assay [24]. In other histological studies, there were minimal and negligible changes between EVH and $\mathrm{OVH}$ in light and electronically microcopy [25-28].

\section{Limitations}

Matching patients with similar criteria as of DM was our limitation.

\section{Ethical issue}

The study was conducted in accordance with the principles of Declaration of Helsinki 1996 version and Good Clinical Practice standards. All subjects signed informedconsent forms.

\section{Abbreviations \\ IHC: Immunohistochemistry; vWf: Von Willebrand factor; eNOS: Nitric oxide synthase; EVH: Endoscopic vein harvesting; $\mathrm{OVH}$ : Open vein harvesting; CABG: Coronary artery bypass graft; CAD: Coronary artery disease; RCT: Randomized clinical trial; e-Caveolin: Endothelial caveolin; IQR: Interquartile range; CVA: Cerebrovascular accident; BMI: Body mass index; BUN: Blood urea nitrogen; FBS: Fasting blood sugar; TC: Total cholesterol; LDL-C: Low density lipoprotein cholesterol; HDL-C: High-density lipoprotein; TG: Triacylglyceride; 2VD: Two-vessel coronary artery disease; 3VD: Three-vessel coronary artery disease; HTN: Hypertension; DM: Diabetes mellitus; SEM: Scanning electron microscopy.}

\section{Competing interest}

The authors declare that they have no competing interests.

\section{Authors' contributions}

MHN: Head of research team \& Research designer. PN: Data analysis \& Data gathering \& Patient follow up. SA: Pathology section. AA: Pathology section. HRR: Pathology section \& Data analysis. All authors read and approved the final manuscript.

\section{Acknowledgement}

Authors would like to thank all patients for their cooperation and permission to publish this article.

\section{Author details}

'Department Cardiac Surgery, Emam Reza Academic Hospital, Mashhad University of Medical Sciences, Mashhad, Iran. ${ }^{2}$ Student Research Committee, Mashhad University of Medical Sciences, No 124., Niloufar 8th, Sadjad Blvd, Mashhad 91878, Iran. ${ }^{3}$ Department of Pathology, Emam Reza Academic Hospital, Mashhad University of Medical Sciences, Mashhad, Iran. ${ }^{4}$ Department of Molecular Pathology and Cytogenetics, Mashhad University of Medical Sciences, Mashhad, Iran. ${ }^{5}$ Student Research Committee, Department of Modern Sciences \& Technologies, School of Medicine, Mashhad University of Medical Sciences, Mashhad, Iran.

Received: 29 March 2014 Accepted: 13 June 2014

Published: 17 June 2014

\section{References}

1. Shekar PS: Cardiology patient page. On-pump and off-pump coronary artery bypass grafting. Circulation 2006, 113(4):e51-e52.

2. Taheri MS, Haghighatkhah H, Tash MH, Bakhshian R, Shakiba M, Jalali A: The prevalence of carotid artery disease in candidates of coronary artery bypass graft. Iran J Radiol 2006, 3(4):221-224.

3. Anvari MS, Boroumand MA, Emami B, Karimi A, Soleymanzadeh M, Abbasi SH, Soleymanzadeh M, Abbasi SH, Saadat S: ABO blood group and coronary artery diseases in Iranian patients awaiting coronary artery bypass graft surgery: a review of 10,641 cases. Lab Med 2009, 40(9):528-530.

4. Nalysnyk L, Fahrbach K, Reynolds MW, Zhao SZ, Ross S: Adverse events in coronary artery bypass graft (CABG) trials: a systematic review and analysis. Heart 2003, 89(7):767-772.

5. Allen KB, Heimansohn DA, Robison RJ, Schier JJ, Griffith GL, Fitzgerald EB: Influence of endoscopic versus traditional saphenectomy on event-free survival: five-year follow-up of a prospective randomized trial. Heart Surg Forum 2003, 6(6):E143-E145.

6. Markar SR, Kutty R, Edmonds L, Sadat U, Nair S: A meta-analysis of minimally invasive versus traditional open vein harvest technique for coronary artery bypass graft surgery. Interact Cardiovasc Thorac Surg 2010, 10(2):266-270.

7. Bitondo JM, Daggett WM, Torchiana DF, Akins CW, Hilgenberg AD, Vlahakes GJ, Madsen JC, MacGillivray TE, Agnihotri AK: Endoscopic versus open saphenous vein harvest: a comparison of postoperative wound complications. Ann Thorac Surg 2002, 73(2):523-528. 
8. Nezafati MH, Nezafati P: Descriptive analysis of endoscopic versus traditional open vein harvest technique for coronary artery bypass graft surgery: report of 1974 casess. Iran Heart J 2014, 14(4):17-22.

9. Krishnamoorthy B, Critchley WR, Glover AT, Nair J, Jones MT, Waterworth PD, Fildes JE, Yonan N: A randomized study comparing three groups of vein harvesting methods for coronary artery bypass grafting: endoscopic harvest versus standard bridging and open techniques. Interact Cardiovasc Thorac Surg 2012, 15(2):224-228.

10. Allen KB, Heimansohn DA, Robison RJ, Schier JJ, Griffith GL, Fitzgerald EB, Isch JH, Abraham S, Shaar CJ: Risk factors for leg wound complications following endoscopic versus traditional saphenous vein harvesting. Heart Surg Forum 2000, 3(4):325-330.

11. Dusterhoft V, Bauer M, Buz S, Schaumann B, Hetzer R: Wound-healing disturbances after vein harvesting for CABG: a randomized trial to compare the minimally invasive direct vision and traditional approaches. Ann Thorac Surg 2001, 72(6):2038-2043.

12. Lopes RD, Hafley GE, Allen KB, Ferguson TB, Peterson ED, Harrington RA, Mehta RH, Gibson CM, Mack MJ, Kouchoukos NT, Califf RM, Alexander JH: Endoscopic versus open vein-graft harvesting in coronary-artery bypass surgery. N Engl J Med 2009, 361(3):235-244.

13. Hussaini BE, Lu XG, Wolfe JA, Thatte HS: Evaluation of endoscopic vein extraction on structural and functional viability of saphenous vein endothelium. J Cardiothorac Surg 2011, 6:82.

14. Rousou LJ, Taylor KB, Lu XG, Healey N, Crittenden MD, Khuri SF, Thatte HS: Saphenous vein conduits harvested by endoscopic technique exhibit structural and functional damage. Ann Thorac Surg 2009, 87(1):62-70.

15. Blann AD, McCollum CN: Von Willebrand factor, endothelial cell damage and atherosclerosis. Eur J Vasc Surg 1994, 8(1):10-15.

16. Chung AW, Au Yeung K, Cortes SF, Sandor GG, Judge DP, Dietz HC, van Breemen C: Endothelial dysfunction and compromised eNOS/Akt signaling in the thoracic aorta during the progression of Marfan syndrome. Br J Pharmacol 2007, 150(8):1075-1083.

17. Vestweber D: VE-cadherin: the major endothelial adhesion molecule controlling cellular junctions and blood vessel formation. Arterioscler Thromb Vasc Biol 2008, 28(2):223-232.

18. Sen CK, Gordillo GM, Roy S, Kirsner R, Lambert L, Hunt TK, Gottrup F Gurtner GC, Longaker MT: Human skin wounds: a major and snowballing threat to public health and the economy. Wound Repair Regen 2009, 17(6):763-771

19. Tashnizi MA, Alamdari DH, Khayami ME, Rahimi HR, Moeinipour A, Amouzeshi A, Seifalian AM: Treatment of non-healing sternum wound after open-heart surgery with allogenic platelet-rich plasma and fibrin glue-preliminary outcomes. Indian J Plast Surg 2013, 46(3):538-542.

20. Kiaii B, Moon BC, Massel D, Langlois Y, Austin TW, Willoughby A, Guiraudon C, Howard CR, Guo LR: A prospective randomized trial of endoscopic versus conventional harvesting of the saphenous vein in coronary artery bypass surgery. J Thorac Cardiovasc Surg 2002, 123(2):204-212.

21. Mendes RG, Simoes RP, De Souza Melo Costa F, Pantoni CB, Di Thommazo L, Luzzi S, Amaral-Neto O, Catai AM, Arena R, Borghi-Silva A: Short-term supervised inpatient physiotherapy exercise protocol improves cardiac autonomic function after coronary artery bypass graft surgery-a randomised controlled tria. Disabil Rehabil 2010, 32(16):1320-1327.

22. Rodrigus IE, Stockman B, Amsel BJ, Moulijn AC: Should we use video-assisted endoscopic vein harvesting as a standard technique? Heart Surg Forum 2001, 4(1):53-55.

23. Black EA, Campbell RK, Channon KM, Ratnatunga C, Pillai R: Minimally invasive vein harvesting significantly reduces pain and wound morbidity. Eur J Cardiothorac Surg 2002, 22(3):381-386.

24. Al Saggaf SM, Ayuob NN, Ali SS, Elhamami M: Endoscopic Saphenous Vein Harvesting (ESVH) Versus Open Saphenous Vein Harvesting (OSVH): a light and electron microscopic study. Egyptian J Histol 2010, 33(2):396-406.

25. Griffith GL, Allen KB, Waller BF, Heimansohn DA, Robison RJ, Schier JJ, Shaar CJ: Endoscopic and traditional saphenous vein harvest: a histologic comparison. Ann Thorac Surg 2000, 69(2):520-523.

26. Meyer DM, Rogers TE, Jessen ME, Estrera AS, Chin AK: Histologic evidence of the safety of endoscopic saphenous vein graft preparation. Ann Thorac Surg 2000, 70(2):487-491.
27. Alrawi SJ, Balaya F, Raju R, Cunningham JN Jr, Acinapura AJ: A comparative study of endothelial cell injury during open and endoscopic saphenectomy: an electron microscopic evaluation. Heart Surg Forum 2001, 4(2):120-127.

28. Fabricius AM, Diegeler A, Doll N, Weidenbach H, Mohr FW: Minimally invasive saphenous vein harvesting techniques: morphology and postoperative outcome. Ann Thorac Surg 2000, 70(2):473-478.

doi:10.1186/1749-8090-9-101

Cite this article as: Nezafati et al:: Immunohistochemistry comparing endoscopic vein harvesting vs. open vein harvesting on saphenous vein endothelium. Journal of Cardiothoracic Surgery 2014 9:101.

\section{Submit your next manuscript to BioMed Central and take full advantage of:}

- Convenient online submission

- Thorough peer review

- No space constraints or color figure charges

- Immediate publication on acceptance

- Inclusion in PubMed, CAS, Scopus and Google Scholar

- Research which is freely available for redistribution

Submit your manuscript at www.biomedcentral.com/submit
C BioMed Central 